\title{
CIUDADES DE FRONTERA E INDUSTRIA AZUCARERA
}

\section{Omar JeReZ}

Profesor Adjunto, Carrera de Antropología, U NJu. Investigador del CONICET.

e-mail: omarjerez@hotmail.com

\section{Mario RabeY}

Profesor Titular, M aestría en Desarrollo Sustentable, U N La - FLACAM

e-mail: mariorabey1@yahoo.com.ar

Cuaderno U rbano N 5, pp. 7-34, Resistencia, A rgentina, J unio 2006 


\section{CUADERNQ 5}

Ciudades de Frontera e Industria Azucarera

\section{Resumen}

El presente trabajo reflexiona acerca de la influencia que tuvo en la constitución de la ciudad boliviana de Bermejo, en particular, y del complejo urbano (que conforma junto a la ciudad argentina de Aguas Blancas), en general, el desarrollo de la industria azucarera. Bermejo se ha constituido en ciudad a partir del desarrollo de tres ejes dinamizadores: (1) la explotación del petróleo, (2) la producción e industrialización de azúcar y (3) el comercio de frontera. Estos tres ejes, especial mente la industria azucarera, le dieron gran impronta y dinamismo a la conformación de la ciudad de Bermejo, a partir del fuerte flujo trasnacional de trabajadores entre Argentina y Bolivia. De esta manera podemos decir, que fueron muchos de aquellos trabajadores migrantes bolivianos en las cosechas azucareras argentinas, que van a participar en la explotación de la caña de azúcar en los primeros años de la década de 1970, y que le dará a Bermejo el impulso para transformase en un importante centro urbano del sur de Bolivia.

\section{Abstract \\ SU GAR CANE INDUSTRY AND CITIESBONDARIES}

This paper analyses the influence of the sugar cane industry development, particularly in the creation of the Bolivian city of Bermejo and generally in the Argentinean city of Aguas Blancas. Bermejo city grew upon three dynamic processes: (1) Oil exploitation, (2) Sugar cane industrialisation and production and (3) the border commerce. These three activities, particularly the sugar cane industry facilitated Bermejo city's grow th upon the dynamism provided by labour flow across the border betw een Argentina and Bolivia. W e could say that those Bolivian w orkers attracted by the sugar cane harvests in Argentina during the early seventies, helped and enhanced to transform Bermejo city into the most important urban centre in southern Bolivia. 


\section{Omar Jerez y Mario Rabey}

Ciudades de Frontera e Industria AzUCarera

\section{INTRODUCCIÓN}

En Jujuy, una provincia ubicada en el extremo noroeste de Argentina, en su frontera con Chile y Bolivia, diversos estudios antropológicos han señalado que el surgimiento y la expansión urbana han estado fuertemente vinculados con el desarrollo de las industrias local es. Esto es así particularmente en el caso de la producción de acero en Zapla, con la ciudad de Palpalá (Ferreiro et al 1990), y del azúcar en Libertador General San M artín con el ingenio azucarero de Ledesma (Karasik 1991) y en San Pedro de Jujuy con el ingenio La Esperanza (Jerez 1995, 1999). Estas industrias y, especialmente, el sistema productivo agroindustrial del azúcar y las transformaciones tecnológicas asociadas a su producción (entre las que se destaca la mecanización de la zafral en algunas regiones) han generado un fuerte dinamismo migratorio.

En trabajos anteriores hemos hecho referencia a la forma en que crecen las ciudades y los distintos tipos de conocimiento (principalmente populares, académicos, políticos y empresariales) que confluyen en la producción y construcción de las ciudades (Rabey et al 1994; Jerez 1995; Jerez y Rabey 1998; Jerez 1999; Rabey y Jerez 2000). Estos trabajos se refirieron a las ciudades argentinas de San Pedro y Ledesma (ambas en la provincia de Jujuy), Orán (en la provincia de Salta) y a la ciudad boliviana de Bermejo. Revisando distintos estudios (Benencia y Karasik 1995; Bisio y Forni 1976; Conti, Teruel y Lagos 1988; Karasik 1987, 1991, 1992; Santamaría y Lagos 1992; Santamaría 1984, 1986; Sassone 1984; Teruel 1993; W hiteford 1977, 1981, entre otros), se hace evidente la correlación entre el crecimiento urbano, la industria azucarera y las migraciones transfronterizas entre Bolivia y Argentina, causadas por la demanda estacional de mano de obra para la cosecha de caña de azúcar. La investigación histórica, para los casos de los ingenios de Jujuy y Salta, identifica dos momentos en la composición y estrategias de captación de la mano de obra para la cosecha de la caña: una de «despegue» de la industria azucarera - entre 1880 a 1920 - , caracterizada por mano de obra de indígenas de las tierras bajas chaqueñas; y otra de «consolidación» - entre 1920 a 1940 - cuando la mano de obra chaqueña fue reemplazada por la de indígenas de las tierras altas andinas de Argentina y Bolivia (Lagos
1- En Argentina se utiliza corrientemente la palabra zafra para designar la cosecha de caña de azúcar. 


\section{CUADERNQ 5}

10

Ciudades de Frontera e Industria Azucarera

y Teruel 1989; Rutledge 1987 a, b). En ambos casos se trata de poblaciones habitantes de espacios socio - cultural es transfronterizos: Ias tierras bajas chaqueñas y las tierras al tas andinas, respectivamente.

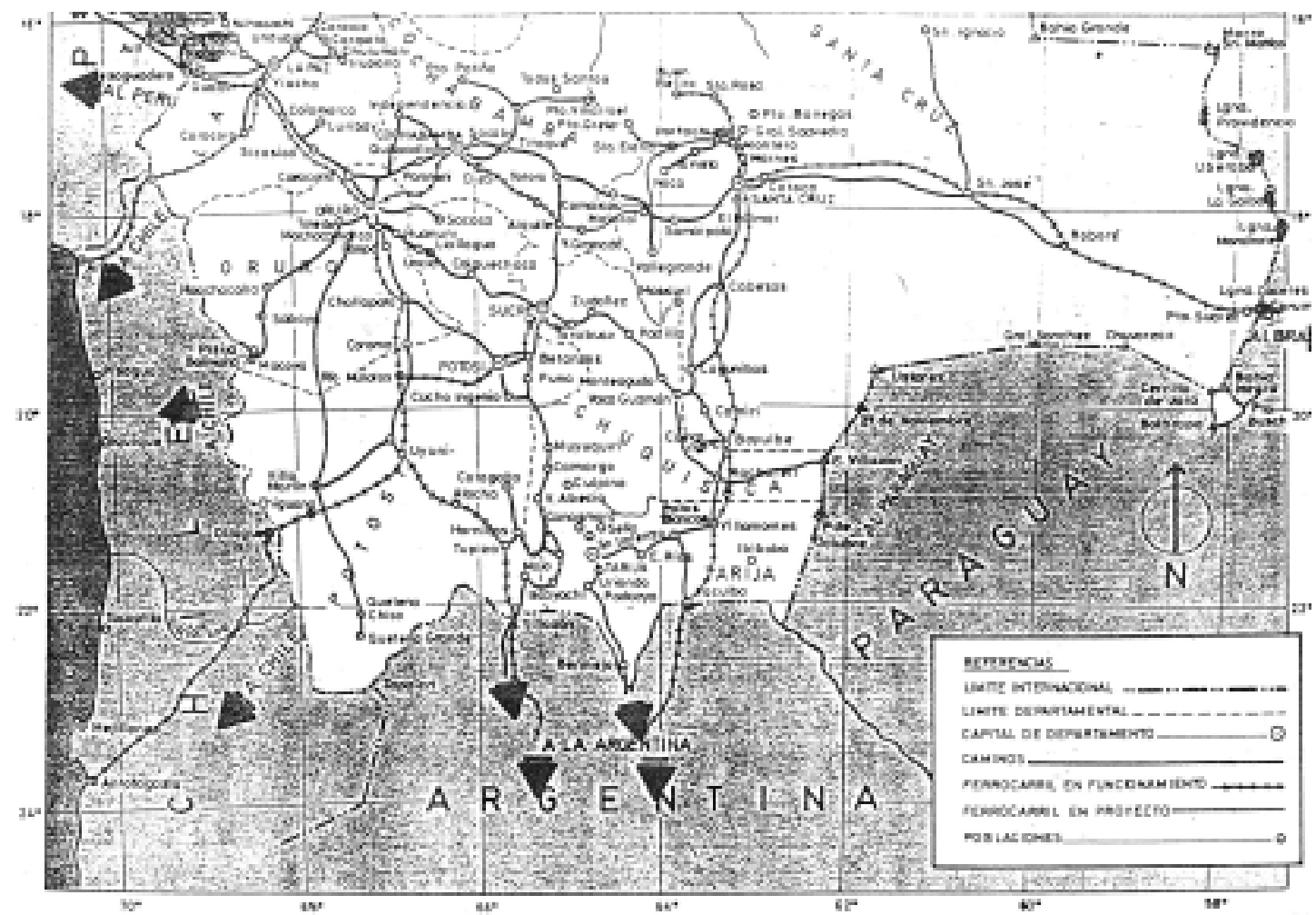




\section{Omar Jerez y Mario Rabey}

Ciudades de Frontera e Industria AzUCARera

Desde los años 60, comenzó un paulatino proceso de mecanización de las cosechas de caña de azúcar que produjo una creciente desocupación de la mano de obra migrante. En un trabajo anterior (J erez y R abey 1998), investigamos la trayectoria de los desocupados que iba dejando la mecanización en el Ingenio La Esperanza, adyacente a la ciudad de San Pedro. Encontramos que, aunque muchos regresaron a su lugar de origen, la gran mayoría se asentó en la ciudad, dando lugar a un sostenido proceso de periferización urbana, así como a una todavía no resuel ta demanda de nuevas tierras a ser incorporadas a la ciudad. U no de los mayores problemas que tiene San Pedro es la falta de disponibilidad detierras para la expansión urbana. La ciudad está prácticamente rodeada por plantaciones azucareras propiedad del Ingenio, de manera que cualquier expansión urbana formal debe hacerse sobre sus tierras. Entonces, la ciudad está creciendo principalmente por la ocupación de hecho por parte de grupos de familias que buscan un lugar para construir sus viviendas. El mecanismo funciona de la siguiente forma, primero la gente ocupa el lugar; luego, los funcionarios ( «los políticos», como los denominan los asentados) negocian con la empresa. Finalmente la tierra se entrega a la provincia, previa expropiación (Jerez 1995, 1999; Jerez y R abey 1998).

El presente trabajo reflexiona acerca de la influencia que tuvo el desarrollo de la industria azucarera en la producción de otra ciudad donde, a su condición agro -industrial, se agrega su situación de frontera: la ciudad boliviana de Bermejo y, en términos más generales, el complejo urbano que conforma Ber-

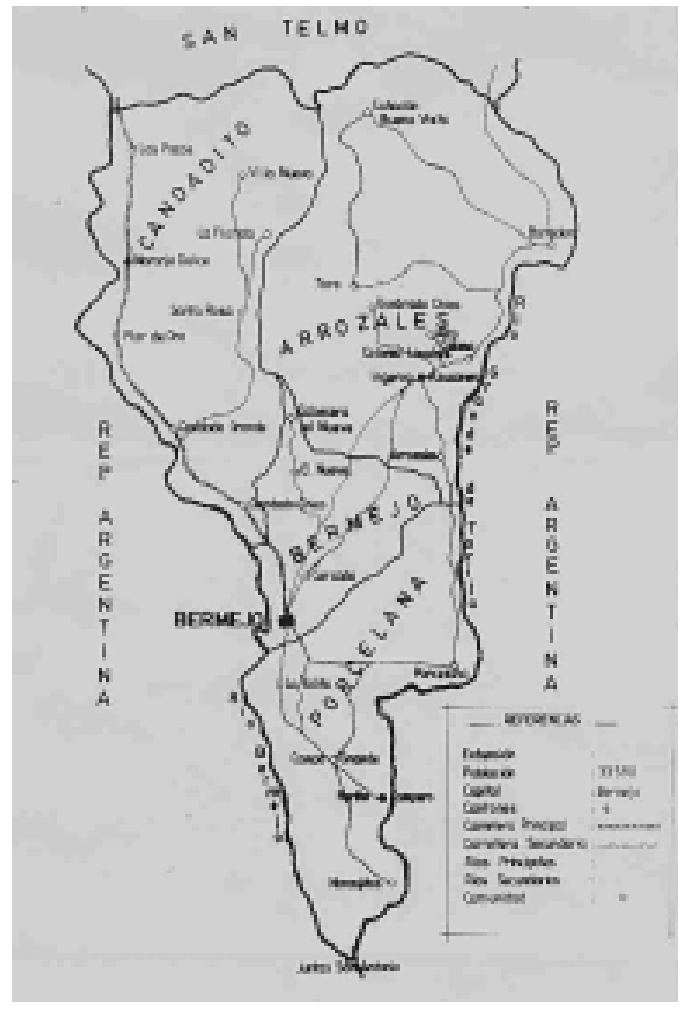




\section{CUADERNQ 5}

12

Ciudades de Frontera e Industria Azucarera

mejo junto a la ciudad argentina de Aguas Blancas. El desarrollo urbano de Bermejo tuvo tres ejes dinamizadores sucesivos: (a) la explotación del petróleo, (b) la producción e industrialización de azúcar y (c) el comercio de frontera. Este último eje está directamente instalado en su condición de ciudad de frontera. El anterior, el azucarero, que fue el más importante, también constituye en este caso un tema de frontera, puesto que la instalación de la producción cañera en Bermejo se vio altamente favorecida por la experiencia laboral de los campesinos andinos del sur de Bolivia en la producción azucarera del noroeste argentino. De hecho, muchos de los trabajadores migrantes bolivianos en las zafras argentinas que fueron quedando desocupados por los procesos de mecanización de la cosecha, comenzaron a participar en la producción de la caña de azúcar en Bermejo desde los primeros años de la década de 1970 , como productores minifundistas y como cosecheros. Fue precisamente el flujo de migrantes permanentes y estacionales para la producción de azúcar, junto con la necesidad de proveer de toda clase de servicios a esa masa creciente de población, lo que explica la transformación de Bermejo del pequeño asentamiento petrolero de fines de los ' 60 en la ciudad que ya era a fines de los ' 80 . Y esta rápida urbanización fue, además, potenciada, por el pequeño comercio transfronterizo, especialmente notable durante los períodos (como el de 1991 - 2001) donde el tipo de cambio favorecía a los pequeños comerciantes bolivianos, cuyo mercado principal eran los compradores argentinos que llegaban hasta allí de gran parte de las provincias de Salta y Jujuy. Entonces, y a diferencia de lo que sucedió en las otras ciudades azucareras de la región (Orán, Libertador, San Pedro, G üemes), todas ellas ubicadas en territorio argentino, Bermejo constituye un caso especial, y particularmente interesante de urbanización, porque combina los procesos agroindustriales con los del comercio informal de frontera.

\section{ASPECTOSMETODOLÓGICOS}

El trabajo de campo se realizó en distintas campañas entre 1996 y 1999. Para el trabajo de campo hemos utilizado metodología etnográfica, basada en el registro sistemático de las perspectivas y recuerdos de los actores involucrados, así como de las estructuras de sus prácticas y discursos. Ello implica la aplicación de varias técnicas cual itativas de investi- 


\section{Omar Jerez y Mario Rabey}

gación social (Guber 1991; H ammersley y Atkinson 1994; Taylor y Bogdan 1990) particularmente las más usual es en el proceso de investigación etnográfico: observación participante, entrevistas abiertas, semiestructuradas y estructuradas, historias de vida.

Como es frecuente en los estudios antropológicos, las entrevistas se aplicaron para complementar los resultados de la observación participante. H emos realizado un conjunto de entrevistas a distintos actores, percibidos localmente como interlocutores legitimad os y conocedores de la realidad y de la historia local, como así también a personas que conocíamos ocasionalmente, en los bares, en los ómnibus (en los que realizábamos la mayor parte de nuestros recorridos), en las estaciones terminales, en los mercados, en las calles, etcétera. Entre ellos se destacan: comerciantes ambulantes, feriantes/vendedores de los mercados de la ciudad; dirigentes gremiales (de gran presencia e importancia en la ciudad de Bermejo); funcionarios y profesionales del gobierno municipal y del gobierno regional; directivos y empleados de la industria azucarera y petrolera; vecinos de la ciudad. H emos creído conveniente no mencionar los nombres y apellidos de las personas para resguardar la identidad y la confidencialidad de la información. Por ello hemos utilizado seudónimos, sólo hemos conservado el origen étnico, la edad y/o la actividad en la que se desempeñan.

Como ya mencionamos, en la frontera Bolivia - Argentina, los estudios real izados ponen énfasis en el papel que ha tenido para la agricultura empresarial la fuerza detrabajo barata constituida, hasta la década del 30, por migrantes estacionales de diversas etnias chaqueñas (Conti et al 1988; H irsch 1999a, 1999b; Lagos y Teruel 1989; Rutledge 1987), y de campesinos de las tierras altas jujeñas y bolivianas a partir de esa época (Bisio y Forni 1976; Rutledge 1987a y 1987b; Santamaría 1984, 1986; W hiteford 1977 y 1981). Con las notables excepciones de W hiteford y $\mathrm{H}$ irsch, ninguno de esos autores ha realizado un análisis del papel de la frontera, así como el de las diferencias de nacionalidad, en el establecimiento de relaciones de trabajo, la construcción de la identidad en la frontera Bolivia - Argentina y los flujos migratorios. Y ningún autor ha trabajado sobre el papel de la frontera en la producción de la ciudad, que es el problema que centralmente enfocamos en este artículo, recurriendo a las fuentes de información etnográfica que mencionamos antes².
2- Esta metodología es la usual en estudios de antropología sociocultural, en cuyo campo se inscribe este trabajo. Los estudios antropológicos relacionados con cuestiones de dinámica demográfica migratoria estacional, como las que ocupan buena parte de la discusión de este artículo, permiten cubrir los vacíos de información que presentan sobre esta cuestión los estudios basados en las técnicas demográficas usuales de análisis de datos censales. En efecto, los censos no reflejan adecuadamente la dinámica migratoria estacional, que solamente puede ser analizada -aunque obviamente sin precisión cuantitativamediante técnicas etnográficas. 


\section{CUADERNQ 5}

14

Ciudades de Frontera e Industria Azucarera

\section{CIUDADESEN LA FRONTERA}

La zona de frontera internacional que estamos analizando es, además, una zona de frontera intercultural entre las tierras altas andinas y las tierras bajas chaqueñas. En esta interface cultural fronteriza, desde el momento de su integración en los estados - nación modernos, seestablecieron los sistemas económicos deproducción más importantes: la explotación petrolera, la extracción de madera, y la industria de la caña de azúcar. En las últimas décadas, fundamentalmente en el lado argentino, se desarrolló además una producción agrícola más activa en las fincas privadas, especialmente de granos y cultivos frutihortícola.

En este sentido, la frontera no debe comprenderse como un límite, sino como un espacio de interacción entre distintas formas de conocimientos y percepciones, como una interface donde interactúan distintas culturas. La coexistencia de diferentes culturas es inherente a la esencia de la frontera. A la vez, la frontera es un lugar donde el control del Estado es laxo. La frontera es también, en muchas ocasiones, un espacio marginal, no sólo por la liminaridad fáctica del contorno estatal, sino marginal en la percepción de sus habitantes, como lugares de soledad, de lejanía, de otredad, de extrañeza, de abandono en el imaginario social. La diversidad cultural y étnica que convergió, a lo largo de su historia, en la ciudad de Bermejo, nos llevó a plantearnos pensar la frontera, más allá de un espacio demarcatorio y limítrofe, como un espacio de interacción. Sin embargo, de la manera en que se ha planteado, los estudios sobre el concepto de frontera para el lugar en donde trabajamos, son fragmentarios y escasos. Ello contrasta con la atención que se le ha estado prestando a los procesos socioculturales y económicos en otras regiones fronterizas como la de M éxico y Estados U nidos. De hecho, durante los últimos años, esa región ha estado atrayendo la atención de numerosos científicos sociales, especialmente antropólogos (Chávez et al 1990; G upta y Ferguson 1992; H eyman 1994, 1995; Kearney 1991; Rosal do 1988; V el ez - I bañez 1999; entre otros autores). A la par, se ha instalado un fuerte debate en torno a parte de esa producción fronteriza mexicano - norteamericana. Por ejemplo, Vila (1999) ha planteado serias dudas acerca de sus soportes teóricos - metodológicos, insistiendo en su falta de soporte empírico, al no estar basados en estudios etnográficos de 


\section{Omar Jerez y Mario Rabey}

Ciudades de Frontera e Industria AzUCarera

primera mano, sino en el uso de etnografías de otros y, principalmente, de piezas literarias, a las cuales los académicos convierten en soporte de "la búsqueda identitaria de un grupo social muy particular (los chicanos de clase media con inserción académica) que con la vida cotidiana de millones de fronterizos (mexicanos, anglos, afroamericanos, indígenas, asiáticos, etcétera) para los cuales la frontera es mucho más que una mera metáfora».

Por otro lado, la frontera entre M éxico y Estados U nidos de N orteamérica presenta una serie de procesos socioculturales y económicos que tienen un carácter visiblemente público: leyes para controlar la migración internacional, maquiladoras, N AFTA eintercambios cultural es. Los mismos procesos - o situaciones comparables- aparecen en la frontera Bolivia - Argentina, con la diferencia de que no se expresan como una cuestión de interés público, ni siquiera en las provincias de Sal ta y Jujuy, cuyos medios de comunicación masiva les prestan muy poca atención. Esto es algo real mente enigmático, si consideramos la situación al tamente conflictiva de la frontera, especialmente en las áreas de tierras bajas, donde se combinan importantes flujos de migración laboral permanente y estacional, contrabando hormiga y una frontera externa de M ercosur (R abey 1995). A demás, y en una dimensión probablemente más significativa que en la frontera M éxico USA, aparece aquí una gran diversidad de etnicidades, como consecuencia de constituir esta zona no sólo un límite internacional, sino una interface entre dos regiones ecoculturales mayores: los Andes y el Chaco.

\section{MIGRACIÓN Y PRODUCCIÓN CAÑERA EN BERMEJO}

Durante la década de 1940 el gobierno boliviano comenzó un plan de colonización en las tierras bajas tropicales. En la década de 1960, al mismo tiempo que los ingenios azucareros de Salta y Jujuy, en Argentina, empezaban a mecanizar la cosecha, en Bermejo comenzaba la producción de caña de azúcar. En menos de cinco años se establecen dos ingenios azucareros. Esto motivó que gran parte de los cosecheros estacional es bolivianos que regresaban a sus comunidades, por el paso de Aguas Blancas / Bermejo, comenzaran a asentarse en el lugar. En 1952, se había producido la R eforma Agraria, se suprimió el 


\section{CUADERNQ 5}

16

Ciudades de Frontera e Industria Azucarera

3- $O$, como lo denominó uno de nuestros informantes "la llegada de más progreso”. latifundio y se redistribuyó la propiedad. En Bermejo esa reforma no tuvo mayores complicaciones por dos motivos: en primer lugar, por la ausencia de terratenientes; en segundo lugar, porque en esta región existía una escasa población que estaba vinculada fundamentalmente a la explotación de hidrocarburos, generando una economía capitalista de enclave, aunque con incipiente desarrollo. $\mathrm{H}$ asta ese momento, la subsistencia de los habitantes de Bermejo dependía casi exclusivamente de la industria petrolera, que en ese momento era estatal. Toda la vida social - escuelas, comercios, clubes, cines, etcéteragiraba al rededor de YPFB (Yacimientos Petrolíferos Fiscales Bolivianos, empresa que se constituyó a partir del cese del contrato con la Standard Oil). YPFB proveía también agua y energía eléctrica.

A partir de la inauguración del camino que une Bermejo con Tarija, a fines de los años ‘50, la ciudad se constituyó en un importante polo de convergencia de distintos grupos de campesinos y ex - mineros de las tierras al tas bolivianas. A proximadamente por la misma época, se asfaltaron las rutas en el lado argentino, lo que favoreció la modernización del lado boliviano de la frontera ${ }^{3}$ e incrementó la salida de los migrantes estacionales bolivianos, especial mente zafreros, a los ingenios argentinos, que paradójicamente ya comenzaban a mecanizar su cosecha.

Además, se intensificó el "contrabando hormiga" de mercaderías de un lado a otro de la frontera. Esta actividad es realizada casi exclusivamente por las mujeres. El flujo migratorio que se generó en los pasos fronterizos entre Argentina y Bolivia - luego de la etapa de despegue de la agroindustria azucarera en Argentina - tuvo una fuerte influencia en la composición cultural y demográfica de la región, y en la consolidación de la industria azucarera en Bermejo. Al importante papel que tuvo la experiencia laboral de los migrantes estacionales de Bolivia hacia Argentina, hay que agregarle la presencia de insumos imprescindibles. Así, las distintas variedades de caña de azúcar fueron introducidas de las dos grandes estaciones experimentales cañeras de Argentina: Colonia Santa Rosa en Salta, propiedad de los grandes ingenios azucareros, y O bispo Columbres en Tucumán, pertenecienteal INTA (Instituto N acional de Tecnología A gropecuaria). Los abonos, herbicidas 


\section{Omar Jerez y Mario Rabey}

Ciudades de Frontera e Industria AzUCarera

e insecticidas, durante muchos años, se llevaban también de la A rgentina. En los últimos años los productores cañeros decidieron abastecerse de Santa Cruz de la Sierra y Cochabamba, ambas ciudades bolivianas.

Luego de cuatro años de la puesta en marcha del ingenio Stephen Leigh, la CBF (Confederación Boliviana de Fomento) pide al gobierno la autorización para ampliar la capacidad de molienda, lo que lleva a la construcción de un segundo ingenio, el M oto M éndez. Posteriormente, en 1977, todo este complejo agroindustrial, incluyendo las dos fábricas y las 600 hectáreas de terreno que rodean al complejo industrial, conformaron una empresa estatal Ilamada Industrias Agrícolas de Bermejo Sociedad Anónima (IABSA). El 49\% de sus acciones fueron del Comité de Desarrollo de Tarija (CODETAR) - un organismo de desarrollo departamental-, y el 51\% siguió perteneciendo a la CBF (8). Durante la realización de los estudios preliminares, la compra de las maquinarias e instalación del Complejo Agroindustrial y la primera década de funcionamiento, se produjo un proceso de colonización en las tierras adyacentes a la fábrica. La Industria A grícola de Bermejo (IAB) actualmente, además de caña de azúcar, produce cítricos, café, maní, arroz, maíz, yuca, papaya y porcinos en pequeña escala ( $M$ endieta R uiz 1984). Esta producción es destinada para la venta en el mercado local. Los cítricos son colocados, además, en Tarija, Potosí y Sucre. La cantidad y la calidad de la producción, al igual que la caña de azúcar, están limitadas por la disponibilidad de riego, cuidado agrícola, tipo de terreno y plagas.

Los colonos que comenzaron a asentarse eran campesinos andinos, en su mayoría quechuas, provenientes de las comunidades del sur de los departamentos de Potosí, Chuquisaca y del Valle Central del Departamento deTarija. Los colonos resultaron beneficiados con terrenos de hasta doce y veinte hectáreas de extensión. La condición única consistía en que, en un plazo no mayor de dos años, los nuevos propietarios debían desmontar y comenzar su actividad agrícola. Los colonos no fueron solamente campesinos. Además "se beneficiaron, [ejerciendo sus influencias políticas] muchos comerciantes, empleados y obreros de YPFB que lograron tener acceso a la propiedad de estas parcelas con superficies que en algunos casos llegaron a las trescientas hectáreas" (V aras C astrillo 


\section{CUADERNQ 5}

18

Ciudades de Frontera e Industria Azucarera

1981). Este proceso posibilitará que se asienten en la región de Bermejo, primero, numerosos trabajadores, y luego, numerosas familias, de origen coya. Posteriormente, estas familias construirán un importante sistema de retroal imentación trashumante entre centros expulsores de mano de obra hacia centros de producción, especial mente agrícolas, entre Bolivia y Argentina. La orientación de los braceros coyas estará fuertemente dirigida por las posibilidades económicas que se produzcan tanto en Argentina como en Bolivia. Así, las continuas migraciones estacionales de trabajadores bolivianos y sus familias para las cosechas en la Argentina han posibilitado que al gunos se asienten definitivamente. Esto trajo como consecuencia, primero, el abandono de la comunidad campesina de donde eran originarios y, segundo, el abandono de la ciudad de Bermejo, hacia Argentina.

La costumbre de trasladarse anual mente hacia el norte argentino, sobre todo hacia las provincias de Jujuy, Salta y Tucumán, se veía reforzada por los lazos de parentesco que estas familias campesinas establecieron en el norte argentino, con el asentamiento definitivo por parte de al gún integrante de su familia. A demás, el mercado laboral en Argentina es más amplio y diversificado: además del azúcar están la construcción, el tabaco, caña, los frutales; y sobre todo, los salarios resultan más el evados que los ofrecidos en Bolivia. Igualmente, los ingresos extrasalariales, tales como la atención médica hospitalaria, otros beneficios sociales y la jubilación por años de servicio, inexistentes hasta 1977 en Bermejo, constituyeron poderosas razones para que miles de familias campesinas cruzaran la frontera. Los ingresos extrasalariales dieron estabilidad a la fuerza de trabajo eventual delos ingenios argentinos:

"A rgentina para nosotros es al go hermoso, para quévamos a decir otra cosa. Allá hay otra forma devida. Hay plata, mejor queacá. A unquetodo cuestemás y nos explotan, los bolivianos estamos contentos con eso. Porqueuno mejora, adelanta" (Carmen, V endedora A mbulante/Cosechera).

"A unqueno nos guste, tenemos queaceptar queA rgentina es mejor, por trabajo, por educación, por salud. Si tenés al go complicado, tenés quepensar en ir a la A rgentina. A hí es más completo todo" (Laura,Profesora). 


\section{Omar Jerez y Mario Rabey}

Ciudades de Frontera e Industria Azucarera

Sin embargo, a la par que se constituía la zona de Bermejo en un importante polo económico, también se constituyó en un importante espacio de información, va a ser considerado como el lugar donde "siempre se sabe algo... por acá viene gente de arriba (por las tierras al toandinas), deSanta Cruz, deA rgentina". Bermejo fue constituyéndose en un espacio de acceso a la información, especial mente desde los relatos de los trabajadores bolivianos que regresaban desde la zafra argentina hacia sus comunidades. Cuando el trabajador estacional regresaba todos los años de trabajar en los ingenios argentinos, volvía con un agregado de prácticas y hábitos urbanos. Los discursos fuertemente peyorativos son frecuentes en muchos bermejeños mestizos - aun los hijos de coyas ${ }^{4}$ - , cuando opinan que los trabajadores golondrinas al regresar, especialmente los coyas, han realizado una serie de modificaciones en sus prácticas cotidianas: "[...] ahora han intentado mejorar la casa [...] antes sedormía en un cuero, ahora seguro quedespués dela zafra sepasaba a un catre, a camas argentinas. Colchones, mesas. jiA $h$, caramba, antes no comían en mesa! M ejores condiciones devida. La comida distinta, aprendierona comer distinto.A prendierona cocinar con carnefresca.H acerlosa losalimentosmás bien cocido, mayor sabor.Comidasdistintas, con máscalorías, con más proténas. Han aprendido a sacar pecho, a no estar encorvado. iiiE so!!!" (A lejandro, Empleado M unicipal).

La región de Bermejo, a partir de la década del sesenta, se convirtió en centro de atracción para las familias campesinas. La región ofrecía tres al ternativas: primero, la posibilidad de la colonización detierras vírgenes; segundo, estaba latente la incorporación como obrero permanente en la empresa azucarera; $y$, tercero, si las dos opciones fracasaban podía participar en el comercio como vendedor, changarín o migrar hacia A rgentina. Algunas familias logran mejorar sus condiciones de vida iniciales. Sin embargo, un grupo aún mayoritario se encuentra viviendo en condiciones paupérrimas.

El cañero proviene de zonas altiplánicas o vallunas que son ecológicamente diferentes de su nuevo lugar de residencia. Se ve obligado a asimilarse rápidamente a ese nuevo entorno natural, para sobrevivir. En su lugar de origen practicaba una agricultura tradicional de subsistencia, combinada con la crianza de camélidos y ovinos; comúnmente se trataba de cultivos de papa, cebada, trigo, maíz, ocas, habas, cultivos que de año en año debían renovarse (Varas Castrillo 1981). En cambio, la caña de azúcar es un cultivo permanente.
4- En las tierras bajas bolivianas (Departamentos de Beni, Santa Cruz, Tarija), es corriente referirse a los originarios de las tierras altas con el nombre de "coya", término con el cual se engloban pertenencias étnicas diversas, especialmente aimarás y quechuas, así como mestizos andinos. 


\section{CUADERNQ 5}

Ciudades de Frontera e Industria Azucarera

Sólo cada siete años debe ser renovado, y no necesita de un constante cuidado, sino que se cumplan determinadas labores cultural es. La nueva situación va a modificar la relación hombre - tierra, haciéndola menos intensa. En las nuevas condiciones, los colonos pueden trasladar su lugar de residencia a centros urbanos, como Bermejo, y visitar semanalmente y quincenalmente sus parcelas, de acuerdo con los requerimientos del ciclo agrícola.

La diferenciación de acceso a los conocimientos (tecnológicos y financieros) antes señalados determina: (a) que al gunos pequeños productores vendan su fuerza de trabajo a los cañeros más prósperos y, por otro lado, (b) que los cañeros prósperos contraten esa mano de obra barata, pues aún con maquinarias, no pueden levantar la cosecha en los terrenos de mayor irregularidad. Además, este cambio de una agricultura de subsistencia, hacia una comercial, Ileva a que la familia recurra al mercado para cubrir todas sus necesidades básicas, cambiando sus patrones de alimentación y de consumo. También la relativa poca dedicación que necesitan los cultivos, unida a las facilidades de transporte y a mejores ingresos económicos, lleva a que los adultos dejen la vida rural, para radicarse en centros poblados como Bermejo, y/o funden nuevos núcleos urbanos, como es el caso de Colonia Linares - próximo al Ingenio Azucarero-, con el objeto de obtener mejores servicios: agua, luz, desagüe, centros educativos y recreativos.

El proceso de competencia en el mercado de trabajo y de la producción comenzó, en los últimos años a generar una polarización social entre los cañeros. Varas Castrillo (1981) estableció hace dos décadas una taxonomía que todavía parece ser apropiada, distinguiendo entre empresarios y tres estratos campesinos.

Los empresarios agrícolas cañeros abarcan el $1 \%$ del total de los productores de caña en Bermejo. Dado que sus parcel as fluctúan entre 100 y 300 has, su producción y productividad resulta importante por la dotación de tierras y también por los medios de producción que poseen (maquinaria agrícola y capital); lo que determina el alto monto de caña que entregan a la empresa. Este subgrupo se caracteriza también por haber introducido el sistema de riego, tractores, mochilas, fumigadoras, herbicidas y fertilizantes. 


\section{Omar Jerez y Mario Rabey}

Ciudades de Frontera e Industria AzUCarera

Los campesinos cañeros acomodados se diferencian de los cañeros empresarios en que no han podido incorporar la tecnología de cosecha. Trabajan sus propios predios y contratan mano de obra. Sus excedentes son canalizados hacia el sector terciario, diversificando así su economía, donde combinan la agricultura con el comercio y el transporte. Algunos invierten sus ganancias en otros núcleos urbanos, especialmenteen Tarijay en ciudades deArgentina.

Los cañeros medios y los cañeros pobres mantienen en sus parcelas otros cultivos que destinan a la venta en el pueblo y una parte para el consumo de la unidad familiar. Los cañeros pobres son campesinos que aun no cultivan o lo hacen en extensiones restringidas; sin acceso al crédito, venden su fuerza de trabajo como obreros eventuales en las fábricas de azúcar, en las parcelas de los cañeros ricos o como jornaleros en el pueblo de Bermejo. A diferencia de los grupos anteriores mantienen fuertes lazos con sus lugares de origen, y siguen explotando sus tierras en las zonas vallunas 0 al tiplánicas.

La taxonomía de Varas Castrillo fue modificada en los Talleres de A utodiagnóstico ( G obierno M unicipal de Bermejo, 2000). En esa oportunidad se estableció el siguiente esquema relacional: (1) propietario pequeño, de una a diez hectáreas; (2) propietario mediano, de diez a veinte hectáreas; y (3) propietario grande, de veinte a más hectáreas. 0 tra clasificación fue establecida por Hernán Zeballos (Gobierno M unicipal de Bermejo, 2000); quien sostiene la siguiente estratificación: infrasubsistentes (cañeros pobres de 0 a 8.99 hectáreas); subsistentes (cañeros pequeños de 9 a 14.99 hectáreas); estacionarios ( cañeros de medianos de 15 a 19.99 hectáreas) y excedentarios (cañeros grandes de 20 a más hectáreas).

M ientras unos pocos cañeros logran acumular capital mejorando sus condiciones de vida, en el otro extremo la mayoría vive en condiciones paupérrimas, sujeta a un círculo de endeudamiento que traba sus potencialidades de producir la tierra adjudicada. Esto se debe a la baja productividad y rentabilidad de la tierra. Un cañero pobre, con cinco hectáreas en plena producción, no al canza a cubrir los gastos de costo. 


\section{CUADERNQ 5}

"[...] el promedio significa 232 toneladas decaña por 5 hectáreas. Con esepromedio un productor cañero no llega a tener un sueldo quelegaranticelo quees su alimentación y su vestimenta en todo el año. Porquerecibeal rededor de 26.000 bolivianosal año. Es decir 5.000 dólaresal año.Con eso él tieneque mantener su actividad, puedeser queesas 5 hectár eas quel as mantenga per sonal mente, pero va a necesitar siempredeal guien quelecolabore, y dealgunos productosquímicos. Eso significa quecon esa plata él tienequetrasladar la producción al ingenio. En promedio estamoshablando de16 bolivianosel flete, más 20 queesla pelada y la cargada, y más una comisión quecobra el quehacela cosecha. Son 7 dólares por 232 toneladas son 1753 dólares, menos los 5000, ya lequedan 3000 dólares. Lequitemos 400 dólares porqueocupa un ayudante. 3000 dólares lequedan, divido entre 12 meses, significa 272 dólares por mes. Significa un sueldo de 1300 bolivianos. [...] no llega a tener un suel do quelepermita vivir dignamente. L 0 queyo leestaba dando, 250 dólares es muy alto. Eso debeser 150 dólares" (M arcos, funcionario de jerarquía deuna cooperativa).

Enviar a los hijos a estudiar en la universidad es un criterio que define a los cañeros ricos, y todos los cañeros consideran importante que sus hijos cumplan al menos sus estudios secundarios. Para los más pobres, la migración hacia Argentina significa, además de la posibilidad de mejorar económicamente, que sus hijos concluyan el ciclo educativo, lo cual a veces puede incluir estudios terciarios y universitarios.

Los cañeros ricos van transformánd ose en capitalistas, porquela cantidad de tierras cultivadas supera la capacidad de la fuerza de trabajo familiar para atender todas las labores, recurriendo así a emplear obreros asalariados en forma casi permanente. Estos asalariados son frecuentemente sus vecinos cañeros pobres, quienes realizan labores de siembra, aporque y deshierbe. Algunos cañeros pobres venden su tierra. Otros lo hacen cuando obtienen trabajo asalariado permanente en la empresa azucarera. Los demás se dedican al comercio o emigran hacia Argentina.

\section{IN CIDENCIA DE LA ETAPA AZU CARERA EN LA POBLACIÓN DE BERM EJO}

Con la instalación de la industria azucarera, la población de Bermejo y todo el territorio de influencia, aumenta considerablemente. 


\section{Omar Jerez y Mario Rabey}

Ciudades de Frontera e Industria AzUCarera

"[...] en 1966 ya empieza a emigrar genteen gran número a Bermejo. Ya había la noticia dela creación del ingenio azucarer o. En 1966 - 1967 ya seempezaron a hacer trabajo dedesmonte, deasentamiento, decolonias. Los colonosvenían dela zona deT upiza, Villazón y deTarija.La partealtiplánica del departamento deT arija y Potosí, del sur. En 1968, comienza la primera zafra y la producción deazúcar, con un ingenio.A partir de66 - 67 ya empieza a tomar importancia la población, porqueya vienen en gran núme rolos habitantes deotraszonas" (D olores, profesora desecundario).

"[...] esta gentevino a asentarsecomo colonos, a col onizar, a tomar propiedad dela tierra, para trabajar en el cultivo dela caña deazúcar. Gran partedeesegrupo no pierdesu identidad con su pueblo originario, porqueviene, seasienta, inicia su trabajo decultivo dela caña.Y lo quehacen es una pequeña vivienda, y otra vez vuelven a su lugar deorigen, en determinadas épocas del año. Trabajan en toda la época dela zafra, haciendo su deshierbe, la mantención desu cultivo, y ahí cuando no hay mucho quehacer sevuelven a su pago.Sonloscolonos coyas potosinos" (Raque, funcionaria municipal).

La discontinuidad en el relevamiento censal dificulta una medición más precisa de la variación demográfica. Sin embargo, podemos ver el incremento de población año a año a partir de los registros del CENECA (Organismo nacional que se encarga de registros estadísticos vinculados a la producción azucarera) y del Informe Anual del Azúcar elaborado por el propio Ingenio. En 1992 el censo nacional dio un total de 21394 habitantes en el sector urbano, y 9.655 en los cantones, correspondientes al sector rural. En el 2000, la Alcaldía estimaba que la población sobrepasaba los 30.000 habitantes. La población aumenta en las fechas de mayo a noviembre, tiempo en que se desarrolla la zafra azucarera. Esto genera un movimiento de gente inusual en la región, de ahí que los vecinos de la ciudad dicen, "cuando no hay zafra [entre enero -junio] está todo silencio". En esta época de silencio, el mayor dinamismo se concentra en los mercados o ferias populares locales, que todo el año tienen una importante actividad, y se acrecienta para las celebraciones de fin de año.

Esta población migratoria, que año a año concurre a trabajar en los ingenios azucareros de Bermejo, proviene de los departamentos andinos de T arija, C huquisaca, Potosí, La Paz, Cochabamba y Oruro. En una encuesta realizada por la Oficina de A sistencia Social de la 
5- Algo similar ocurre en las cosechas de Santa Cruz, en las tierras bajas de piedemonte ubicadas en el centro de Bolivia, especialmente en los cultivos de caña, arroz y maíz. En los períodos de máximo requerimiento de mano de obra, básicamente para las cosechas, se cubre el déficit recurriendo a trabajadores vinculados a través de relaciones de parentesco y compadrazgo, quienes fluyen anualmente a la región desde los lugares de origen de los colonos (Blanes 1984:384).
I glesia (OASI), se puede ver la influencia migratoria de la población coya originaria de las tierras altoandinas bolivianas, especialmente de los sectores rurales. De hecho, la población de Bermejo representa el centro urbano más importante en el triángulo sur, después de Tarija y Yacuiba. Esto se debe al carácter receptor de la región, especial mente de trabajadores altoandinos que trabajan temporalmente en la cosecha de caña de azúcar.

Los cañeros bermejeños van a buscar a los trabajadores en sus propias comunidades de origen, donde contratan a sus paisanos ${ }^{5}$. Como hay bastante demanda de mano de obra, uno de los mecanismos a los que se recurre es el adelanto de un porcentaje del sueldo para tener un seguro de que no irán con otro cañero.

Varas C astrillo (1981) señala que durante los últimos años de la década del '70, "el rápido incremento poblacional en la región se dio en el lapso de 20 años, pues de sólo 180 personas censadas por la Alcaldía en el pueblo de Bermejo en 1957, se pasó en 1976 a 13.022, más las 7.013 personas dispersas en los cincos cantones circundantes". Desde finales de los '70, hasta el momento de escribir este trabajo, el aumento de trabajadores fue creciendo, a la par que fue expandiéndose la frontera agrícola, en relación con la consolidación de la explotación agroindustrial del azúcar. Esta industria atrajo a cientos de familias campesinas de la zona altiplánica y de los valles de los departamentos de Potosí, Chuquisaca y Tarija a colonizar el triángulo de Bermejo y zonas adyacentes:

"El boom es tremendo, ya para todo eso, la población estaba constituida, había como 10.000 personas. Y vienen para la zafra, gente de la zona alta de Tarija, primera, y dela parte sureña dePotosí, y al gunos de la parte sur eña de Sucre, es gente del altiplano, pero de esta parte del altiplano. V ienen acá a trabajar en la zafra y al gunos se quedan. E ran trabajadores temporales. Los trabajadores bolivianos, los coyas seiban a trabajar a la zafra argentina, y al gunos vinieron de paso y se quedaron" (D olores, profesora secundaria). 


\section{Omar Jerez y Mario Rabey}

Ciudades de Frontera e Industria AzUCarera

"[...] Il egan los Chapacos ${ }^{6}$. Entonces con los polos de desarrollo, les daban más comodidades y facilidades a las per sonas, a los colonos que comienzan a llegar para dotarse de tierras. A parecey dice 'yo quiero plantar caña', y ledicen 'ahí tienela tier ra, trabaje' " (R aquel, funcionaria municipal).

Estos trabajadores se incorporaron a la economía regional, regulada por el ingenio, ya sea como cosecheros, o como trabajadores de la fábrica. Los zafreros llegan a Bermejo acompañados de sus hijos y mujeres, y las cuartas. Las cuartas son parientes 0 amigos que trabajan en las unidades domésticas zafreras y participan en la parte de la cosecha que le corresponde a la unidad. Son reclutados entre familias que - por enfermedad, viudez, orfandad o deudas - ceden a los hijos de 12 a 15 años (o más, en el caso de mujeres), quienes en forma conjunta realizaran las labores de corte, pelado y carga de la caña de azúcar. Permanecen el tiempo que demora la cosecha (de cuatro a siete meses) en campamentos 0 en habitaciones construidas por sus patrones. Estos lugares son denominados campamentos zafreros, ubicados generalmente sobre los mismos campos de cultivos, en cual quier esquina del cañaveral, sobre la tierra aún sin sembrar 0 anegada. La mayoría de los campamentos es construida con ramas y barro (palo pique), el techo de chapa u hojas de plátano y el piso de tierra. La mayoría de estos campamentos consta de dos o tres recintos, aproximadamente de cinco por tres metros, donde se ubican los grupos, con un promedio de tres o cuatro unidades domésticas por habitación. N o tienen agua potable ni baños. U na situación similar se observa en los campamentos cosecheros de los ingenios de Santa Cruz (Blanes 1984).

En la cosecha de caña (corte, deshoje y cargada), la familia campesina se organiza y divide el trabajo de acuerdo con el sexo y la edad. Los trabajadores designan un jefe de todo el grupo, quien se responsabilizará de todas las relaciones del grupo familiar con los cañeros (propietarios) de la plantación. U n encargado, que trabaja para el contratista, apostado al costado de los campos de caña en donde se va acumulando lo que se cosecha, es el que recibe la marcada y entrega la caña a los camiones, para su traslado a la fábrica.
6- Chapacos es el nombre popular que reciben los campesinos de Tarija. 


\section{CUADERNQ 5}

Según el Plan Participativo de Desarrollo del M unicipio de Bermejo (Gobierno M unicipal de Bermejo, 2000), «la ocupación y empleo y los ingresos son generados principalmente por la Industria Azucarera de Bermejo, que emplea a más de 1000 trabajadores. En tanto, los que se dedican al comercio informal llegan aproximadamente a dos mil, según los datos de afiliación al Sindicato del rubro (el sindicato del rubor se denomina Federación de Gremialistas). Por otro lado existe ocupación en distintas actividades, especialmente en la construcción, servicios bancarios, hoteles, empleados públicos (municipio, escuelas, personal de seguridad, salud, etcétera) y profesionales en general.

Considerando los ingresos, el equipo técnico de OASI, junto a la Alcal día (Gobierno M unicipal de Bermejo, 2000), sostienen que las familias pueden ser estratificadas en familias de ingresos altos, ingresos medios y de ingresos bajos. Las familias de ingresos altos son las de cañeros con una extensión considerable de cañas de azúcar, y que en al gunos casos son también comerciantes; también integran este sector los profesionales de mejores ingresos. Entre las familias de ingresos medios están las de cañeros con menores cantidades de hectáreas de caña, que les permite vivir adecuadamente sin un medio de ahorro o ganancia sustantiva; también el resto de los profesionales, empleados públicos y trabajadores de alto rango de Industrias Agrícolas de Bermejo y los comerciantes con un mediano capital de trabajo.

Las familias de ingresos bajos están constituidas por productores cañeros denominados pequeños, que apenas ganan para subsistir y preparan la próxima cosecha a través de préstamos de sus asociaciones. Están también los que viven en las zonas más al ejadas y producen maní, maíz, hortalizas, papa y otros, que no pueden sacar al mercado por tener caminos que en épocas de lluvia son intransitables y durante el resto del año son de difícil acceso. También están los peones, zafreros, albañiles, trabajadores que ofrecen su fuerza detrabajo en forma temporal, los comerciantes ambulantes, personal de servicio domiciliario.

En cuanto a la participación de la mujer en la producción, que tiene un rol muy importante, debido a que en las actividades agropecuarias las mujeres aportan entre un $35 \%$ a 


\section{Omar Jerez y Mario Rabey}

Ciudades de Frontera e Industria AzUCarera

$40 \%$ de trabajo, tanto en las actividades de preparación de suelos, siembra, labores culturales, cosecha y comercial ización como el cuidado de animales. Son mayoría en el comercio. Además de su rol en la preparación de alimentos, la atención de los niños y del hogar.

La familia, junto a sus cuartas, que llega por primera vez, luego de participar en la zafra, y habiendo adquirido experiencia urbana, al cabo de un tiempo puede participar en otras actividades, además de las labores de la cosecha. Estas actividades varían entre vendedores ambulantes en el mercado, puestos de comidas (actividades básicamente femeninas), cargadores o pasadores de contrabando hormiga ("bagayeros") y en otras actividades que no requieran una mayor inversión inicial más que la fuerza de trabajo propia. La mayoría de las veces se comienza como ayudante de al bañil, cocina, transporte, etcétera.

A demás del personal vinculado con la administración y producción de azúcar, el ingenio demanda y genera la presencia de servicios tales como talleres de reparación, proveedurías de repuestos, comercios de venta de ropa, comestibles, transporte, y demás tiendas que proveen artículos de lo más variados. Este efecto multiplicador permitió que el primer desarrollo de la economía local, basado en la actividad petrolera, no disminuyera, cuando ésta comenzó a reducir su explotación.

"La parteagroindustrial tienemayor efecto multiplicador, porqueestá el cañero, el dueño del terreno.El primero siembra y luego va ampliando su cultivo, después ya es patrón, y necesita gentequelehaga el trabajo. E so además genera quel os cañer os queson más demil, otros les vendan comestibles, ropas. E ntonces como tienequeirsea sus parcel as, y hay al gunos queno tienen sus vehícul os, aparecen otros quetie nen platita y compran un vehícul o para transporte. 0 tros ponen tiendas para proveer insumos. Otrosalquilantractores. Llega la zafra y senecesita cual quier cantidad demano deobra para la cosecha, senecesita mucho transporte. Senecesita a losadmini strativos queestán trabajando en el ingenio. Entonces para hacer azúcar hay mucha gentetrabajando. Por eso di go queesunagentemultiplicador másimportanteque la partehidrocarburífera" (Ricardo,empresario). 


\section{CUADERNQ 5}

Ciudades de Frontera e Industria Azucarera

\section{CONCLUSIONES}

Las decisiones políticas sobre el sector agrario, llevadas adelante por el Estado boliviano en las décadas del '50 y '60, provocaron el auge económico y la correspondiente urbanización de la región donde está Bermejo. Bermejo comienza a tomar fisonomía de ciudad, sobrela base de su consolidación como centro político -administrativo, comercial y de servicios, en relación con la agroindustria azucarera.

Respaldada en el crecimiento de Bermejo, también se expandió Aguas Blancas, un pequeño poblado ubicado enfrente, en la margen argentina del río, que se cargó principalmente de funciones comerciales. Comenzó así una breve pero dinámica historia de crecimiento complementario y oscilante, en la que cada uno de los dos asentamientos creció más en los períodos en los que se vio favorecido por las equivalencias entre las monedas de ambos países y, consecuentemente, por los flujos comerciales de compra. Sin embargo, fue Bermejo el asentamiento con mayor crecimiento demográfico y ello se debea dos motivos: [a] el carácter minorista e informal del comercio en Bolivia, frente a su mayor concentración y formalidad en Argentina; [b] la condición de centralidad de Bermejo respecto de un área rural densamente poblada. A estos factores debeagregarse el mejoramiento del camino entre esta ciudad y Tarija - y a través de ésta, con otras ciudades bolivianas- , lo que facilitó enormemente el flujo de personas y bienes. Durante los primeros años de la década de 1990, esta asimetría se acentuó por causa de dos factores que a su vez se potenciaron mutuamente: [a] un tipo de cambio que favorecelos intercambios de Bolivia a la Argentina; [b] el mantenimiento dela atracción colonizadora del triángulo de Bermejo sobre los campesinos de las tierras altas bolivianas, en un contexto de cada vez mayor escasez de tierras aptas para el cultivo de caña. La combinación sinérgica de ambos factores ha venido produciendo, junto con el retroceso demográfico deA guas Blancas - hoy con unos mil habitantes - , el crecimiento explosivo de Bermejo - donde ya habitan casi cuarenta mil personas- , y su periferización que ya comienza a afectar las áreas cañeras más próximas. 


\section{Omar Jerez y Mario Rabey}

Ciudades de Frontera e Industria AzUCarera

Paralelamente en Argentina, y ya desde inicios de la década del '70, un considerable número de zafreros que participaba en las cosechas, a partir de la modernización y mecanización queda sin trabajo. Se produce una dispersión que culmina con el asentamiento dealgunos de ellos en los centros urbanos argentinos más próximos, otros regresan a su lugar de origen. No podemos dejar de señalar la importancia que tiene para la actual producción frutihortícola en territorio argentino la presencia de trabajadores bolivianos, la mayoría en situación de ilegalidad.

Estos trabajadores regresaban con dinero a Bolivia, comenzando a construir la agroindustria azucarera en Bermejo (Rabey 1994). No podemos dejar de ver el proceso de constitución y consolidación de la industria azucarera en el sur de Bolivia, sin entender la relación y la incidencia que tuvo en ésta la industria azucarera argentina. Esta última significó para muchos zafreros bolivianos una instancia de aprendizaje. $\mathrm{H}$ acia fines de los años ' 50 , luego de la reforma agraria y de la consecuente política de colonización en el oriente de Bolivia (Santa Cruz de la Sierra), fue la misma gente la que les señaló el rumbo a las autoridades y técnicos del Estado, sobre los tipos de producción que eran factibles en la región, basadas en la comparación con otras regiones geográfica y climáticamente similares a Bermejo.

La ciudad de Bermejo es una «ciudad nueva». Se conformó a la luz de tres ejes dinamizadores, la explotación de petróleo, la agroindustria azucarera y el comercio de frontera. El primer eje, la explotación del petróleo se realiza desde principios del siglo $X X, y$ es lo que va a dar lugar al asentamiento del primer poblado en el lugar. Actualmente continúa con la explotación, pero en manos privadas. El segundo eje, la agroindustria azucarera, le da a Bermejo la conformación de ciudad: vinculado con esta industria se instalan talleres, empresas de transporte, hoteles, casas de comidas, comercio en general. El tercer eje es el comercio de frontera. El gobierno de Bolivia, en 1985, establece a través del Decreto Supremo 21060, una serie de medidas que produjo un giro en la vida social, política y económica del país. Esas medidas consistieron básicamente en: (a) la reducción del déficit fiscal con congelamiento de salarios, aumento del precio de la nafta y 
7- Paradójicamente, fue un gobierno del MNR y el mismo presidente, Víctor Paz Estensoro, que en la revolución del '52 habían llevado adelante una serie de medidas que combinaban democratización y nacionalismo - voto universal,

reforma educativa, reforma agraria, estatización de las empresas privadas-, quien en 1985 comienza, con la sanción del Decreto Supremo 21060, la aplicación de una serie de medidas que condujeron a las privatizaciones de todas las empresas estatales. Semejantes transformaciones económicas dirigidas desde el Estado, se produjeron en Argentina desde 1989, aunque sus antecedentes históricos comenzaron a desarrollarse desde el Gobierno Militar de 1976/1983 (Cortés 1990). El gobierno nacional en manos del Partido Justicialista aplicó una serie de medidas económicas, cuyas consecuencias fueron la disminución del empleo estatal y la concesión a empresas privadas de la gran mayoría de los servicios públicos antes provistos por empresas del Estado (transporte ferroviario, construcción y mantenimiento de rutas, gas, electricidad, agua, teléfonos, aerolíneas). Esto produjo un reacomodamiento del mapa social y económico, y el surgimiento de "nuevos pobres” (Minujin 1992; Minujin y Kessler 1995). reducción de gastos del Estado; (b) un cambio libre y por lo tanto variable de la moneda; (c) despido masivo de trabajadores del estado y sus empresas; (d) liberalización total del mercado, libertad de precios y libre oferta y demanda, arancel único de importaciones; (e) fomento de las exportaciones, y (f) reforma tributaria (De M esa et al 1997:689) ${ }^{7}$.

Con la aplicación de estas medidas, una de las consecuencias de mayor impacto fue el cierre de las minas, pues se retiraron los subsidios que brindaba el Estado a las empresas mineras. A partir de ese momento se produjo una dispersión de mineros y decampesinos, hacia los distintos centros urbanos ( principal mente La Paz), más tarde hacia los departamentos del oriente y sur boliviano, entre los que se destacan Tarija y Santa C ruz.

El cierre de las minas produjo la desarticulación de las economías campesinas que estaban vinculadas con la actividad minera. De manera que la forzosa migración afectó tanto a mineros como a campesinos, de origen coya - quechua- . El gobierno boliviano otorgó indemnizaciones a los ex -mineros, y la promesa de una relocalización en distintos puntos del país, con el fin de reducir el impacto negativo de tal medida y proveer de medios para posibilitar su reinserción a la actividad económica. Hoy, la promesa de la relocalización todavía es esperada por los campesinos y mineros de origen coya.

\section{BIBLIOGRAFÍA}

Benencia, R. y G. Karasik. 1995. Inmigración limítrofe: los bolivianos en Buenos Aires. CEAL.

Bisio, R y F.Forni. 1976. "E conomía deenclavey satelización del mercado detrabajo rural. El caso delos trabajadores con empleo precario en un Ingenio azucarero del noroesteargentino". BuenosA ires, En: Desarrollo Económico, 61(16):3-56.

Blanes, J. 1984. De los Valles al Chapare. Cochabamba.

Chávez, L. R., E. T. Flores, y M. López - Garza. 1990. "H ere Today, G one Tomorrow? U ndocumented Settlersand I mmigration Reform". H uman Organization, 49:193- 205. 
Conti, V.; A. Teruel y M . Lagos. 1988. M ano deobra indígena en los ingenios a principios desiglo. En: Conflictos y Procesos dela H istoria Argentina Contemporánea. CEAL.

Cortés, R. 1990. El empleo urbano argentino delos ' 80 . Tendencias recientes y per spectivas. En: Bustelo, E. y E. I suani (E ditores) M ucho, poquito o nada. Crisis y alternativas de política social en los ' 90 . UNICEF - SigloXXI.

De M esa, J.; T. G isbert, Teresa y C. M esa G isbert,. 1997. H istoria de Bolivia. La Paz: Ed. Gisbert.

Ferreiro, J. P.; D. G onzález y S. A rguello. 1992. "Y al principio era la fábrica:U na aproximación a la problemática dela identidad sociocultural en Pal palá". Cuadernos 4:145 - 152.F HyCS,U N Ju.

Gobierno M unicipal de Bermejo. 2000. Plan de Desarrollo M unicipal de Bermejo 1998 -2000. H onorableA Icaldía M unicipal deBermejo y O SI (O ficina deA sistencia Social dela I glesia).

Guber, R. 1991 El Salvaje M etropolitano. A la vuelta de la Antropología Postmoderna. Reconstrucción del conocimiento social en el trabajo de campo. Buenos A ires: L egasa.

Gupta, A., y J. Ferguson. 1992. Beyond "C ulture": Space, I dentity, and thePolitics of D ifference.Cultural Anthropology, $76-23$.

H ammersley, M. y P. Atkinsonl. 1994. (1983). Etnografía. Barcelona: Paidós.

H eyman, J. M cc. 1994. "TheM exico - U nited States Border in A nthropology: A Critiqueand R eformulation". Journal of Political Ecology, 1:43-65.

Heyman, J. M cc. 1995. "Putting Power in the A nthropology of Bureaucracy: the Immigration and $\mathrm{N}$ aturalization Serviceat theM exico - U nited StatesBorder". Current Anthropology, 36(2).

H irsch, S. 1999a. "M baporenda: El lugar dondehay trabajo. Migraciones G uaraníes al nor oesteargentino". $\mathrm{N}$ oticias de Antropología y A rqueología. A rgentina.

H irsch, S. 1999b. "ConstructingI dentitiesand CrossingBoundariesamongtheG uaraní Indians of Bolivia and A rgentina". Culturelink, 28.

Jerez, 0. 1995. "Queremos unterreno propio. El conocimiento y la narrativa popular para reconstruir una historia barrial". En: Gravano, A. (comp.). M iradas urbanas. Visiones barriales. Diez estudios de antropología urbana sobre cuestiones barriales en regiones metropolitanas y ciudades intermedias: 153-177. M ontevideo: N ordan.

Jerez, 0. 1998. "Los procesos deurbanización en el sur boliviano. El Caso Bermejo". En: Teruel, A y 0. Jerez (Comp.) Pasado y presente de un mundo postergado. Estudios de arqueología, historia 


\section{CUADERNQ 5}

Ciudades de Frontera e Industria Azucarera

y antropología sobre el Chaco y el piedemonte surandino.Jujuy:EDU NJu.

Jerez, 0. 1999. DeEvacuados a A sentados: una etnografía de la periferia urbana. Jujuy: ED U NJu. Jerez, 0. y M. Rabey. 1998. "L a construcción del espacio en la periferia urbana: E I caso deSan Pedro de Jujuy".En:Cuadernos deAntropología Social. Instituto deCiencias Antropológicas, U BA .

Karasik, G . 1991 "La mecanización en la industria azucarera jujeña:El discurso delos agentes sociales". En: Cuadernos, 2: 13-15.FH yCS, U NJu.

Karasik, G. 1992. "M igrantes campesinos y diferenciación social en Jujuy”. En: Cuadernos 4: 137 - 144. FHyCS,UNJu.

Karasik, G. 1987. El control de la mano de obra en un Ingenio Azucarero. El caso Ledesma (Pcia. de ujuy). D ocumento deT rabajo. ECIRA.Serie: EstructurasSociales Regionales. Investigaciones, №4.

Kearney, M . 1991 "Borders and Boundaries of Stateand Self at theEnd of E mpire".J ournal of $\mathrm{H}$ istorical Sociology, 4:52-74.

Lagos, M . y A. Teruel. 1989. “C omposición del sector laboral en la industria azucarera jujeña en la etapa dedespegue". En: Cuadernos 1.FHyCS,U NJu.

M endieta R uiz, R . 1984. Industrias A grícolas de Bermejo. Su repercusión económica y social regional y nacional. Bermejo: D ocumentos del AB (Industria A zucarera Bermejeña).

M inujin, A. 1992. "En la rodada". En: A M inujin y otros. Cuesta A bajo. Los nuevos pobres: efectos de la crisis en la sociedad Argentina.U NICEF/Losada.

M inujin, A. y G. Kessler. 1995. La nueva pobreza en la A rgentina. Buenos A ires: Planeta.

Rabey, M . 1994. Diagnóstico sobre las causas socioambientales de la expansión del Cólera.LaPlata:FLACAM.

Rabey, M. (coordinador). 1995. Proyecto de Prevención de Endemias en la frontera argentino - boliviana. Resultado 1 A vances del nvestigación. FLACAM y Fundación Catalana deG as.

Rabey, M . y 0. Jerez. 2000. "La sustentabilidad está en la gente". E n: Rabey, M . y 0. Jerez (Comp.) Procesos de urbanización en Argentina: una mirada antropológica. Jujuy: ED U NJu.

R osaldo, R .. 1988. "I deology, Place, and Peoplewithout Culture". Cultural Anthropology 3:77 - 87. (Versión revisada, "Border Crossings," en Rosaldo 1989: 196 - 217).

Rutledge, I. 1987a. Cambio Agrario e Integración. El desarrollo del Capitalismo en Jujuy: 1550-1960. Jujuy:ECIRA - CICSO.

R utledge, I. 1987b. "La integración del campesinado detierrasaltas en la economía azucarera del nortede 
Argentina, 1930 - 1943". En: D uncan, K \& I. Rutledge. La tierra y la mano de obra en A mérica Latina: 229 - 254. M éxico: F.C.E.

Santamaría, D. 1984. "A cceso tradicional a la fuerza detrabajo rural, política detier rasy desarrollo capitalista. E I caso dela agricultura decaña deazúcar en el noroesteargentino". En: R evista Paraguaya de Sociología. №21.pp. 117 - 130. A ño 60.

Santamaría, D. 1986. "M igración laboral y conflicto I nterétnico. El caso delos migrantesindígenastemporarios a losingeniosazucareros saltojujeños". En: Estudios M igratorios Latinoamericanos, N ㅇ: 357 - 375.

Santamaría, D y M . Lagos. 1992. "H istoria y etnografía delastier ras bajas del norteargentino. Trabajo realizado y per spectivas". En: Anuario del IEH S, VII.

Sassone, S. 1984. "Tendencias dela migración boliviana en Salta y Jujuy". En: M igraciones. Temas y ensayos. №5:5 - 27. Centro A rgentino deD ocumentación y Estudios M igratoriosScalabriniano.

Taylor, S. J. y R. Bogdan. 1990. (1984) Introducción a los métodos cualitativos de investigación. BuenosA ires: Paidós. (Introduction to qualitative reserch methods: The search for meanings. N ew York: John W iley and Sons)

Teruel, A. 1993. "Población, mano deobra y transformación social en J ujuy a fines del siglo X IX y comienzos del XX ". En:J Jjuy en la H istoria. A vances de Investigación, U nidad del nvestigación en Historia Regional,U NJu.

Varas Castrillo, M . N . 1981 Plantación y economía campesina. Análisis del proceso de descampesinización en el sur Boliviano. TesisdeM agíster en Antropología, Pontificia U niversidad Católica del Perú.

Vélez - Ibáñez, C. 1999. Borders Visions: M exicans Cultures of the Southw est U nited States. U niversity of A rizona Press.

Vila, P. 1999 (ms) "L a teoría defrontera versión norteamericana: una crítica desdela etnografía". Trabajo pre sentado en el Seminario F rontera, naciones eidentidades. Instituto deD esarrollo E conómico y Social.

W hiteford, S. 1977. "A rticulación social y poder: el zafrer o y el contexto dela plantación azucarera". En: H ermitte, E.\& L.Bartolomé(compiladores),Procesos deArticulación Social:91-109.CLACSO,A morrortu Editores.

W hitheford, S. 1981 W orkers from the north. Plantations bolivian labor and the city in northw est Argentina. A ustin: $U$ niversity of T exasP ress. 
